Article

\title{
A Numerical Simulation of the "1907" Kaiyuan Tornado Weather Process in Liaoning, Northeast China
}

\author{
Yiping Wang *, Tong Wang, Pu Yang and Wei Xue
}

check for

updates

Citation: Wang, Y.; Wang, T.; Yang, P.; Xue, W. A Numerical Simulation of the "1907" Kaiyuan Tornado Weather Process in Liaoning, Northeast China. Atmosphere 2022, 13, 219. https:// doi.org/10.3390/atmos13020219

Academic Editors: Elenio Avolio, Stefano Federico and Mario Marcello Miglietta

Received: 7 December 2021

Accepted: 26 January 2022

Published: 28 January 2022

Publisher's Note: MDPI stays neutral with regard to jurisdictional claims in published maps and institutional affiliations.

Copyright: (C) 2022 by the authors. Licensee MDPI, Basel, Switzerland. This article is an open access article distributed under the terms and conditions of the Creative Commons Attribution (CC BY) license (https:// creativecommons.org/licenses/by/ $4.0 /)$.
School of Atmospheric Sciences, Nanjing University, Nanjing 210023, China; MG1928049@smail.nju.edu.cn (T.W.); 2109853jse20002@student.must.edu.mo (P.Y.); mg20280046@smail.nju.edu.cn (W.X.)

* Correspondence: wypfyyd@nju.edu.cn

\begin{abstract}
From 17:00 to 18:00 local standard time (LST) on 3 July 2019, a rare strong tornado occurred in Kaiyuan, Liaoning Province, northeast China. NCEP/NCAR $0.25^{\circ} \times 0.25^{\circ}$ reanalysis data and WRF4.0 numerical prediction models were used to carry out the numerical simulation. Double nesting was adopted, and the horizontal grid distance was $9 \mathrm{~km}$ by $3 \mathrm{~km}$. Based on the observation data of China meteorological observation stations, surface and upper charts, Doppler radar data, Himawari(HMW)-8 satellite images and numerical simulation results, the mesoscale structure and mechanism of the tornado were studied. The results show that: (1) At the northwest edge of the subtropical high, and the northeast cold vortex located in Northeast China, when the transverse trough moves southward, cold air is supplied continuously. Under the joint influence of the surface northeast cyclone, these are the main synoptic features of the tornado; (2) The northeast cold vortex cloud system was located at the junction of Heilongiiang and Jilin Provinces, and a squall line cloud system is formed. The tornado occurred at the tail of the squall line, and the strongest echo reached $65 \mathrm{dBZ}$. A mesocyclone, a $20 \mathrm{~km}$ northwest-southeast convergence belt, V-shaped gap, echo overhang structure and tornado vortex feature (TVS) were detected by the Doppler radar; (3) Before the tornado occurred, dry and cold air intruded from the northwest of the cold vortex, and a water vapor convergence zone appeared south of the squall line. The water vapor saturation zone with $80 \%$ relative humidity in northeast China was concentrated at $700 \mathrm{hPa}$, and the $20 \%$ dry column dropped down to $500 \mathrm{hPa}$ between 115 and $124^{\circ} \mathrm{E}$ from the west. On the $850 \mathrm{hPa}$ physical fields, there was a $-20 \times 10^{-5} \mathrm{~s}^{-1}$ convergence zone, and a $16 \times 10^{-5} \mathrm{~s}^{-1}$ divergence belt appeared south and north of the squall line. A negative vorticity belt and a positive vorticity belt appeared south and north of the squall line, respectively. Kaiyuan is located at the smallest vertical shear, which is the junction place of three large vertical shear belts; (4) After 10:00 LST, the westerly wind 20 (10) $\mathrm{m} \cdot \mathrm{s}^{-1}$ dropped to $400(800) \mathrm{hPa}$ between 126 and $127^{\circ}$ E. The northerly gale at $300 \mathrm{hPa}$ north of $45^{\circ} \mathrm{N}$ moved southward. The rising center of the low level at 17:00 LST at approximately $45^{\circ} \mathrm{N}$ moved southward, and a sinking center appeared above it; (5) Several pairs of positive and negative vorticity columns formed between the lower troposphere and the place where the tornado occurred. There was convective instability at the lower level. CAPE increased, 0-3 km vertical wind shear increased, and LCL decreased remarkably during the afternoon.
\end{abstract}

Keywords: tornado; northeast cold vortex; squall line; mesocyclone; vertical wind shear

\section{Introduction}

A tornado is a severe convective disastrous weather system that can cause heavy casualties and property losses. Due to its characteristics of a small spatial scale, short life history and complex wind field, it is very difficult to forecast a tornado with shortterm timeliness. Currently, forecasting can only occur in the short-term and nowcasting stage. Many contemporary scholars have conducted in-depth and extensive research on tornadoes; most of them in northeast China occur under the background of a northeast cold vortex [1]. Most tornadoes are mesocyclone tornadoes, but some mesocyclones can 
develop into tornadoes [2]. When the height between the cyclone bottom and the ground is less than $1 \mathrm{~km}$, the occurrence probability of tornado is approximately $40 \%$ [3]. Tornado vortex feature (TVS) detected by radar is an important basis for tornado approaching early warning [4]. The occurrence of tornadoes requires large convective available potential energy (CAPE) and strong 0-6 km layer vertical wind shear [5]. It is more conducive to the occurrence of tornado, where large vertical wind shear is concentrated in the lower height rather than $0 \sim 6 \mathrm{~km}[6,7]$. Due to the lack of observation data, numerical prediction models have become an important tool in studying tornadoes. Lewellen et al. (2000) conducted highly idealized large-eddy-resolving simulations of tornadoes [8]. Zhang L. et al. (2021) found that a rear inflow jet descending from the mid-level to surface contributed to the formation of a bow echo and resulted in damaging local winds [9]. Above an EF4 tornado that occurred in Funing, northern Jiangsu Province, China, five nested forecast experiments were run in the WRF model, with the horizontal grid spacing of the inner-most nest being $4000,1333,444,148$, and $49 \mathrm{~m}$, although a tornado-like vortex did not develop until the grid spacing was $444 \mathrm{~m}$ or less [10]. Strong midlatitude weather systems from the north in the spring and summer seasons is apparently the context with the most favorable conditions for tornadoes [11]. Recently, in order to expand tornado research, many simulations of tornadoes with high resolutions have been performed. The intensity of a tornado on the $50 \mathrm{~m}$ grid reaches the high end of category 3 on the Fujita scale (F3), whereas the corresponding simulated tornado on the $100 \mathrm{~m}$ grid reaches F2 intensity [12]. The structures of the multiple subtornadic-scale vortices were similar to that of tornadic vortices in certain respects [13]. Initially the radar-observed tornadic vortices were detected aloft, when they subsequently descended, which led to tornadogenesis [14]. Ensemble-based probabilistic tornado forecasts based upon near-surface wind and/or vorticity fields at $10 \mathrm{~m}$ above the surface produce skillful forecasts of tornadoes in terms of area under the relative operating characteristic curve, with probability swaths extending along and to the northeast of the observed tornado path [15]. Trajectory-based analyses of vorticity components and their time evolution reveal that the tilting of low-level frictionally generated horizontal vorticity plays a dominant role in the development of vertical vorticity near the ground [16]. Closer examination of the genesis of the tornado-like vortex (TLV) suggests that a strong lowlevel updraft is critical in converging and amplifying vertical vorticity associated with the mesovortex [17]. A deep upper-level damping zone is used to prevent upper-level disturbances from affecting the low-level vortex [18]. In the full-wind drag experiment, a tornado develops around $25 \mathrm{~min}$ into the simulation and persists for more than $10 \mathrm{~min}$; in the environmental-only drag experiment, no tornado occurs [19]. The secondary rear-flank downdraft (RFD) surge played a key role in tornadogenesis by barotropically transporting the large streamwise vorticity associated with the environmental low-level veering shear toward the surface [20]. The tornado was generated at the leading edge of a rear-flank downdraft (RFD) outflow surge [21]. The frictional term is the dominant vorticity source responsible for the vortices at both the pretornadic and tornadogenesis times [22].

In summary, the above studies are useful for understanding the structural characteristics of tornadoes. Small-scale systems are bred and developed by large- and medium-scale systems, which are inseparable from the energy, instability conditions and trigger mechanism provided by the large-scale circulation background. In this paper, conventional surface and upper synoptic charts, satellite images, Doppler radar data, encrypted observation data, $6 \mathrm{~h} \mathrm{NCEP} / \mathrm{NCAR} 0.25^{\circ} \times 0.25^{\circ}$ reanalysis data, and WRF numerical simulations are used to study this case. The aim of this research is to find some large-scale weather background and meso- and microscale system characteristics to reveal the environmental conditions conducive to the occurrence of tornadoes, so the forecast accuracy can be improved, and the forecast validity can be prolonged. 


\section{Case Overview and Synoptic Conditions}

\subsection{Disaster Analysis}

Between approximately 17:17 and 17:47 LST on 3 July 2019, rare severe convective weather events, including severe tornado, hail, and short-term heavy precipitation, occurred in Kaiyuan (42.3 $\left.\mathrm{N}, 124.0^{\circ} \mathrm{E}\right)$, Liaoning Province, China [23]. It occurred $0.5 \mathrm{~km}$ north of Jinying village $\left(42.5949^{\circ} \mathrm{N}, 123.9987^{\circ} \mathrm{E}\right)$, Jingouzi town, Kaiyuan city, and then it moved southeast; the distance covered was approximately $15 \mathrm{~km}$. According to the Kaiyuan meteorological observation station, the maximum instantaneous wind speed was $23.0 \mathrm{~m} \cdot \mathrm{s}^{-1}$ at 17:46 LST, reaching above Beaufort force 9. From 17:00 to 18:00 LST, the precipitation was $25 \mathrm{~mm} \mathrm{~h}^{-1}$. According to on-site disaster investigations, the intensity of the tornado reached level 4 of China's meteorological industry standard (equivalent to EF4 in the United States). Many villages in Kaiyuan city were affected, with many houses, electricity and communication infrastructure seriously damaged [24].

\subsection{Synoptic Situation Analysis}

At 08:00 LST on 3 July 2019, a northeast cold vortex appeared at the 500, 700, and $850 \mathrm{hPa}$ isobaric charts, which were all located in western Heilongjiang Province. As cold vortexes split out transverse troughs continuously, stepped troughs were formed. (Figure $1 \mathrm{a}-\mathrm{c}$ ). The $500 \mathrm{hPa}$ cold vortex was $-16{ }^{\circ} \mathrm{C}, 560$ dagpm. Kaiyuan was under the control of the northwesterly flow at 500 and $700 \mathrm{hPa}$, and because it was located behind the trough, it was southwesterly at $850 \mathrm{hPa}$. The areas of Shangdong, Anhui, Henan, and Jiangsu provinces were controlled under the $20^{\circ} \mathrm{C}$ warm core. At 08:00 LST on 3 July, at the surface chart, a $1005 \mathrm{hPa}$ low-pressure center appeared in the central and western regions of Heilongjiang and Jilin provinces. Subsequently, at 17:00 LST, the pressure of the low center dropped to $1002 \mathrm{hPa}$, and it reached the junction of Liaoning, Jilin, and Inner Mongolia. Kaiyuan was located $100 \mathrm{~km}$ southeast of the low center, i.e., $\boldsymbol{\Delta}$ in Figure $1 \mathrm{~d}$. There appeared an inverted trough, which started from the lower center and then moved through central Jilin, and reached in central Heilongjiang. There was weak anticyclonic circulation west of the inverted trough and a small high pressure of $1004 \mathrm{hPa}$ at the east. The northeast cold vortex was over the northern end of the inverted trough, and the southern end was located in the center of the low surface pressure. Of course, from other aspects, at 17:00 LST, the inverted surface trough in northeast China may also be an occlusion front; thus, the tornado occurred near the occlusion point, which was $100 \mathrm{~km}$ away southeast.

The northeast cold vortex (560 dagpm, $-18^{\circ} \mathrm{C}$ ) is deep (Figure $2 \mathrm{a}, \mathrm{b}$ ), and its center falls south of Heilongjiang, where a vortex can be seen at 700 and $850 \mathrm{hPa}$ (Figure 2c).

With the strengthening of the extension of the west high ridge to the northeast, the north wind jet in the west of the cold vortex strengthened, guiding the colder air in the north to accelerate southward. At the same time, due to the strong eastern subtropical high, the southwest airflow in front of the upper trough was sped up. There was a warm tongue extending from the southwest at the low level of $925 \mathrm{hPa}$. The 08:00 LST surface weather chart (Figure 2d) showed 1005 and $1004 \mathrm{hPa}$ low-pressure centers in central Heilongjiang and central Jilin, respectively. There was a cold front that lay from Heilongjiang, central Jilin, to western Liaoning; at the same time, there was a warm front east of Heilongjiang. Subsequently, at 14:00 LST, a $1003 \mathrm{hPa}$ low-pressure center was located in central Jilin, and the other $1002 \mathrm{hPa}$ center was near Kaiyuan. The small northern cold front moved southeast. Southwest Liaoning, Hebei, Beijing, and Shandong were under the control of northwest upper-level flow, and the weather was clear; as a result, the surface area temperature was above $35^{\circ} \mathrm{C}$ in the afternoon. Guided by southwesterly winds in front of the upper trough, unstable energy was continuously transmitted to northeast China. From 08:00 to 17:00 LST, at $500 \mathrm{hPa}$, the transverse trough in northeast China turned vertical, a $-16^{\circ} \mathrm{C} 564$ dagpm cold vortex center moved southward over Kaiyuan, and the southwest airflow in front of the upper trough strengthened under the obstruction of the eastern subtropical high. At $850 \mathrm{hPa}$, a $9^{\circ} \mathrm{C} 138$ dagpm cold vortex moved eastward to the junction of Heilongjiang and Jilin, $70 \mathrm{~km}$ northeast of Kaiyuan, and there was a transverse trough over Kaiyuan. 
At 17:00 LST (Figure 1d), a $1002 \mathrm{hPa}$ low-pressure center was present at the junction of Jilin and central Liaoning, and the other $1003 \mathrm{hPa}$ center was east of Jilin. A cold front lay from central Liaoning to northern Hebei, and a warm front lay from the low center to the east. An inverted surface trough extended northward from the junction of Jilin and Liaoning to the north central part of Heilongjiang. When the tornado occurred in Kaiyuan city, Liaoning Province, at 17:17 LST, it was approximately $100 \mathrm{~km}$ southeast away from the low center; then, it moved approximately $15 \mathrm{~km}$ southeast, and it lasted approximately $30 \mathrm{~min}$.
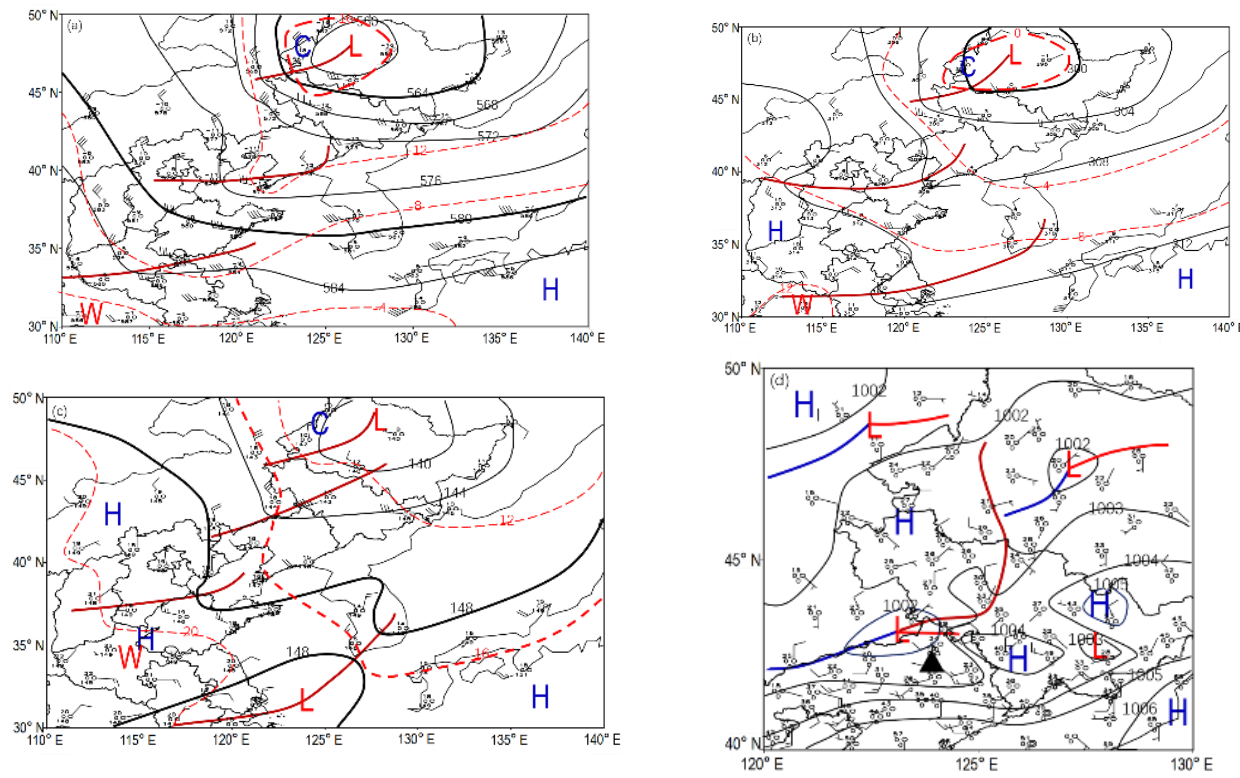

Figure 1. Upper synoptic charts (a) $500 \mathrm{hPa}$, (b) $700 \mathrm{hPa}$, (c) $850 \mathrm{hPa}$ at 08:00 LST, and (d) surface synoptic chart at 17:00 LST, 3 July 2019. Black contours in (a-c) are isoheights (unit: dagpm). Black contours in (d) are isobars (unit: $\mathrm{hPa}$ ). A full bar is $4 \mathrm{~m} \cdot \mathrm{s}^{-1}$. In (d), the blue lines are cold fronts, the red lines are warm fronts, and the brown line is an inverted trough. Kaiyuan is marked with a black triangle.

\subsection{Analysis of Satellite and Doppler Radar}

At 08:00 LST on 3 July 2019, a cold vortex cloud system appeared at the junction of Heilongjiang and Jilin; then, intruded by dry and cold air from its northwest side, a squall line cloud system formed in the southeast, and the southwest flowed at the west of the subtropical high.

Subsequently, it continued to develop and grow; the rear side was neat, which indicated that the dry cold air was relatively strong. Obstructed by the strong southeast subtropical high, the northeast cold vortex moved slowly eastward, and the squall line was almost stationary. At 16:00 LST, a $100 \mathrm{~km}$ long and $20 \mathrm{~km}$ wide stratiform cloud belt stretched westward at the tail of the squall line, $100 \mathrm{~km}$ northeast of Kaiyuan. Then, at 17:00 LST, it rapidly grew into a $-47^{\circ} \mathrm{C}$ oval cloud block, with gaps to the northeast and southeast, indicating that northwest airflow intruded to the northeast and southeast airflow intruded to the southeast. At 18:00 LST (Figure 3a,b), the TBB decreased to $-52{ }^{\circ} \mathrm{C}$. The head was very smooth; therefore, the dry and cold air in the northwest was strong and there is a gap in the $-52{ }^{\circ} \mathrm{C}$ cloud block, indicating that southeast air intruded at the upper level. Thus, a cyclonic circulation formed over Kaiyuan. At 16:00 LST, a supercell with a length of approximately $200 \mathrm{~km}$ forms near Jinzhou on the north side of Liaodong Bay. At 17:00 LST, it reached between Jinzhou and Yingkou, and the TBB (black body brightness temperature) increased to $-57^{\circ} \mathrm{C}$. At 18:00 LST, the TBB decreased to $-52^{\circ} \mathrm{C}$. The northeast boundary of the supercell was consistent with the southwest boundary of the squall line; both were in the northwest-southeast direction, indicating that their airflow directions were the same. At 17:17 LST, at the tail of the squall line, a tornado occurred in Kaiyuan, Liaoning Province. 
The occurrence of a supercell precedes that of the tornado; therefore, it can be considered that the supercell provided the southeast jet for the triggering of the tornado.
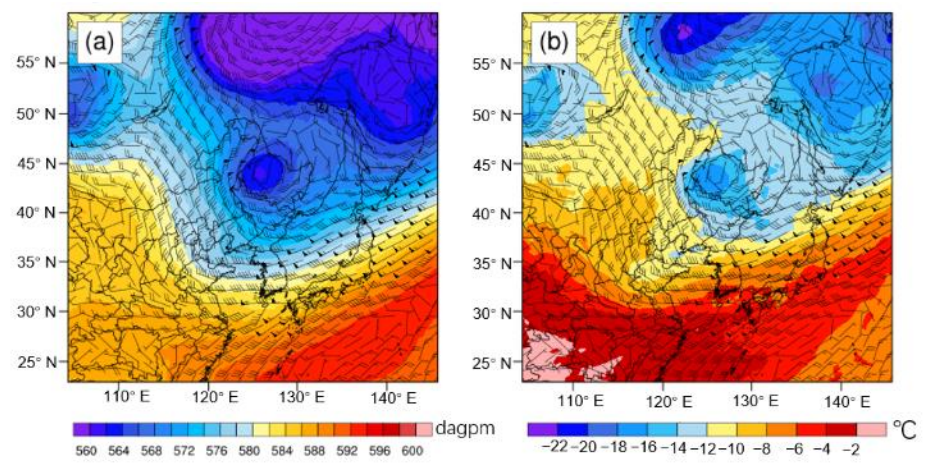

$52^{\circ} \mathrm{N-ight} \mathrm{(m)}$

Sea Level Pressure (hPa)

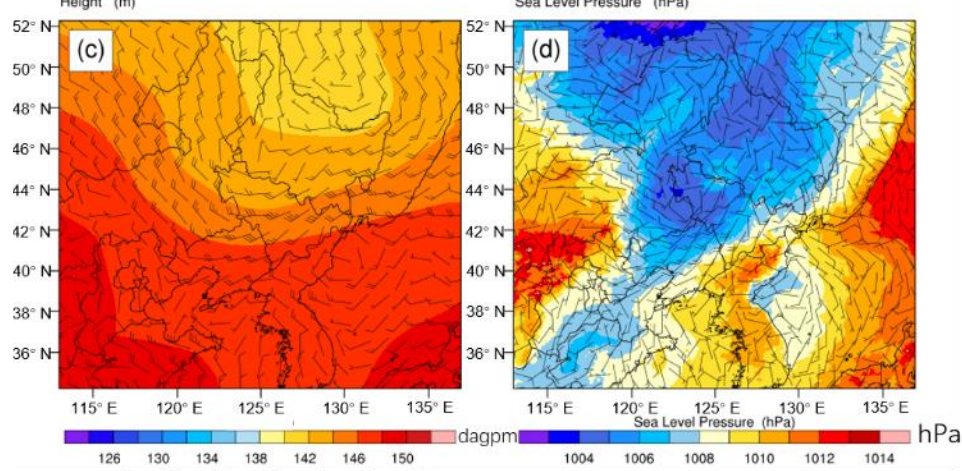

Figure 2. (a) Potential height (shaded areas, dagpm) and horizontal winds at $500 \mathrm{hPa}$; (b) temperature (shaded areas, ${ }^{\circ} \mathrm{C}$ ) and horizontal winds at $500 \mathrm{hPa}$; (c) potential height (shaded areas, dagpm) and horizontal winds at $850 \mathrm{hPa}$; (d) pressure (shaded areas, $\mathrm{hPa}$ ) and horizontal winds at sea level at 08:00 LST on 3 July 2019. A full bar is $4 \mathrm{~m} \cdot \mathrm{s}^{-1}$.
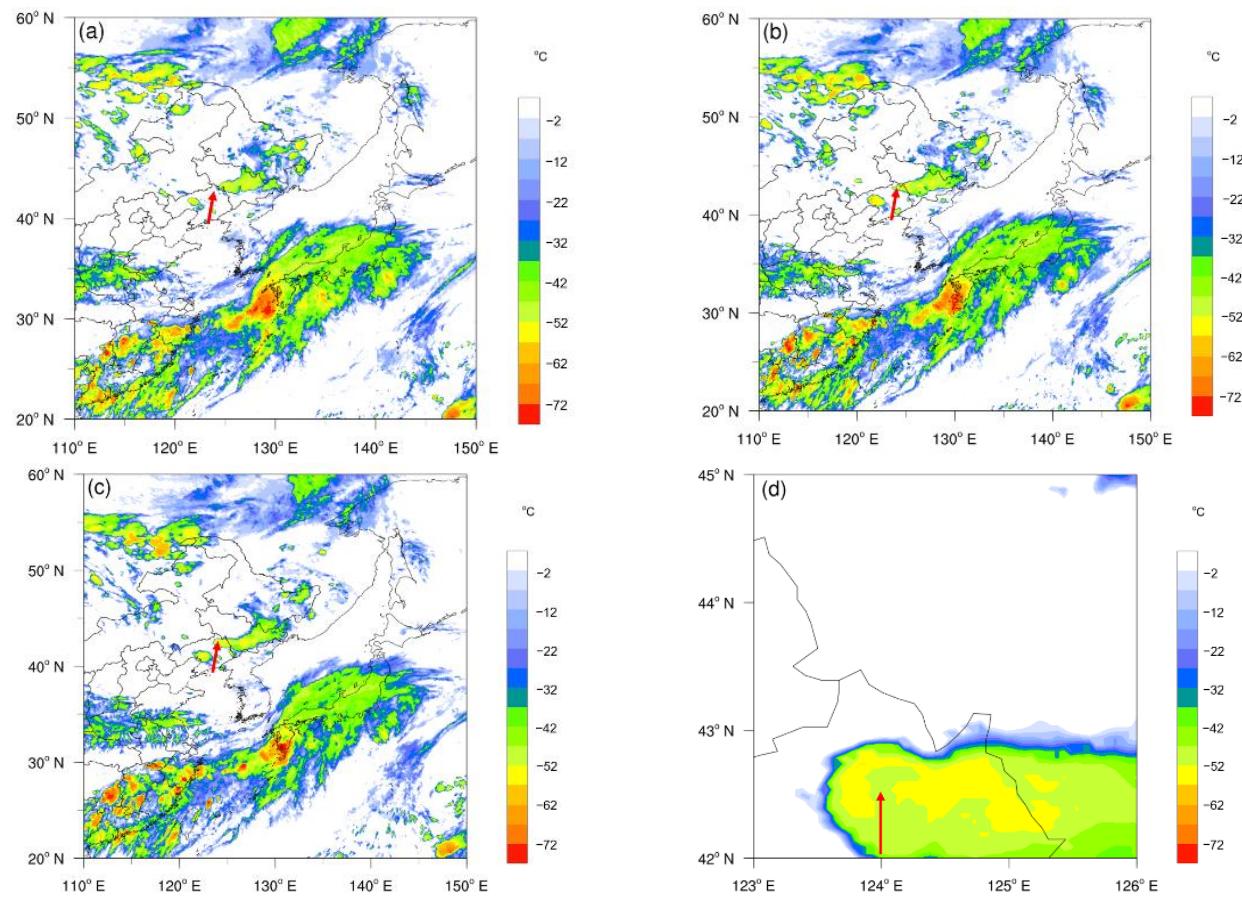

Figure 3. The HMW-8 satellite image (TBB, unit: ${ }^{\circ} \mathrm{C}$ ) at (a) 16:00 LST, (b) 17:00 LST, and (c) 18:00 LST on 3 July 2019. (d) Enlarged view of the squall line tail in (c). The red arrows point to where the tornado appeared. 
The observation on the $0.5^{\circ}$ elevation Doppler velocity map of the Shenyang radar station approximately $60 \mathrm{~km}$ southwest of Kaiyuan at 16:27:21 LST showed that a $20 \mathrm{~km}$ northwest-southeast convergence zone appeared at a height of $3.4 \mathrm{~km}$ and $70 \mathrm{~km}$ northeast of Kaiyuan, with a $10.0 \mathrm{~m} \cdot \mathrm{s}^{-1}$ velocity center and a $-27.0 \mathrm{~m} \cdot \mathrm{s}^{-1}$ center, respectively.

At 17:00:26 LST, the $0.5^{\circ}$ elevation reflectivity map showed that there was an east-west squall line echo zone $75 \mathrm{~km}$ northeast away. On the lines of Huinan, Dongfeng, Xifeng, and Kaiyuan, the strongest echo was $60 \mathrm{dBZ}$, between Kaiyuan and Xifeng. Next, the squall line at Kaiyuan grew stronger, whereas the other parts weaken; then, it was completely broken from the other parts, and the radar echo became the strongest: $65 \mathrm{dBZ}$. The squall line developed and moved southward, whereas the Kaiyuan part moved less and grew continually in the northwest-southeast direction. The $6^{\circ}$ elevation Doppler velocity map showed that there was a pair of positive and negative velocity centers $9 \mathrm{~km}$ north of Kaiyuan, with the greatest velocities of $15.0 \mathrm{~m} \cdot \mathrm{s}^{-1}$ and $-31.0 \mathrm{~m} \cdot \mathrm{s}^{-1}$, respectively; velocity ambiguity appeared, and the convective system tilted from north to south with height. At 17:27:58 LST, the $3.3^{\circ}$ elevation Doppler velocity map showed that a pair of positive and negative velocities centers appeared $5 \mathrm{~km}$ above Kaiyuan (Figure $4 \mathrm{a}$ ), $16.0 \mathrm{~m} \cdot \mathrm{s}^{-1}$ and $-31.0 \mathrm{~m} \cdot \mathrm{s}^{-1}$. The sum of the absolute values of the two centers was greater than $45 \mathrm{~m} \cdot \mathrm{s}^{-1}$, and the distance between the two centers was approximately $20 \mathrm{~km}$; this is called TVS, which is a typical tornado characteristic. A mesocyclone appeared $3 \mathrm{~km}$ from the tail of the squall line. Velocity pairs also appeared on other elevation velocity diagrams of $0.5^{\circ}, 1.5^{\circ}$, $2.4^{\circ}, 4.5^{\circ}, 9.9^{\circ}$, and $14.6^{\circ}$, tilting southwest with height, and the height of the vertical wind shear center decreased. At 17:22:30 LST (Figure 4b), near Kaiyuan, a V-shaped gap appeared southeast of the rear of the squall line, and a V-shaped gap also appeared in the north; they both lasted until 17:39:01 LST. On segment $\mathrm{AB}$ on the $0.5^{\circ}$ elevation reflectivity map at 17:22:30 LST (Figure 4c), on the reflectivity vertical profile, the high reflectivity echo area tilted to the inflow side (northwest) with height, reflecting the weak low-level echo area and the mid- and high-level echo overhang structure, with the maximum exceeding $65 \mathrm{dBZ}$. The V-shaped gap echo south of the squall line tail indicated that the strong southeast inflow entered the updraft, whereas the north inflow indicated that the strong northwest inflow entered the downdraft and could cause destructive gales. At 18:12 LST, the Kaiyuan echo was completely broken from the other part of the squall line.

\subsection{Design of Numerical Experiments}

The advanced research WRF (ARW) modeling system [25] has been in development for the past nineteen years. Version 4.0 has been available since June 2018. The ARW is designed to be a flexible, state-of-the-art atmospheric simulation system which is portable and efficient on available parallel computing platforms. The ARW modeling system is suitable for use in a broad range of applications, across scales ranging from meters to thousands of kilometers. This study was performed by NCAR, which is publicly available $0.25^{\circ} \times 0.25^{\circ}$ reanalysis data. One-way nested grids were employed (Figure 5). The centers of Domain1 and Domain2 were at $45.0^{\circ} \mathrm{N}$ and $125.0^{\circ} \mathrm{E}$, with grid spacings of 9 and $3 \mathrm{~km}$, respectively. The numbers of grid points were $480 \times 480$ and $721 \times 661$, respectively. There were 33 layers in the vertical direction. The simple ice phase scheme and KainFritsch cumulus parameterization scheme were used. The rapid radiative transfer model (RRTM) and the Dudhia scheme were employed for longwave and shortwave radiative flux calculations, respectively; the Mellor-Yamada-Janjic (MYJ) TKE scheme was utilized for the planetary boundary layer; and the unified Noah land surface model was also used. The integrations were performed for $24 \mathrm{~h}$ from 20:00 LST, 2 July 2019, to 20:00 LST, 3 July 2019. Examining the geopotential height fields of 500, 700 and $850 \mathrm{hPa}$ at 08:00 and 20:00 LST, as well as the surface pressure field, it was observed that these were basically consistent with the actual meteorological observation fields. 


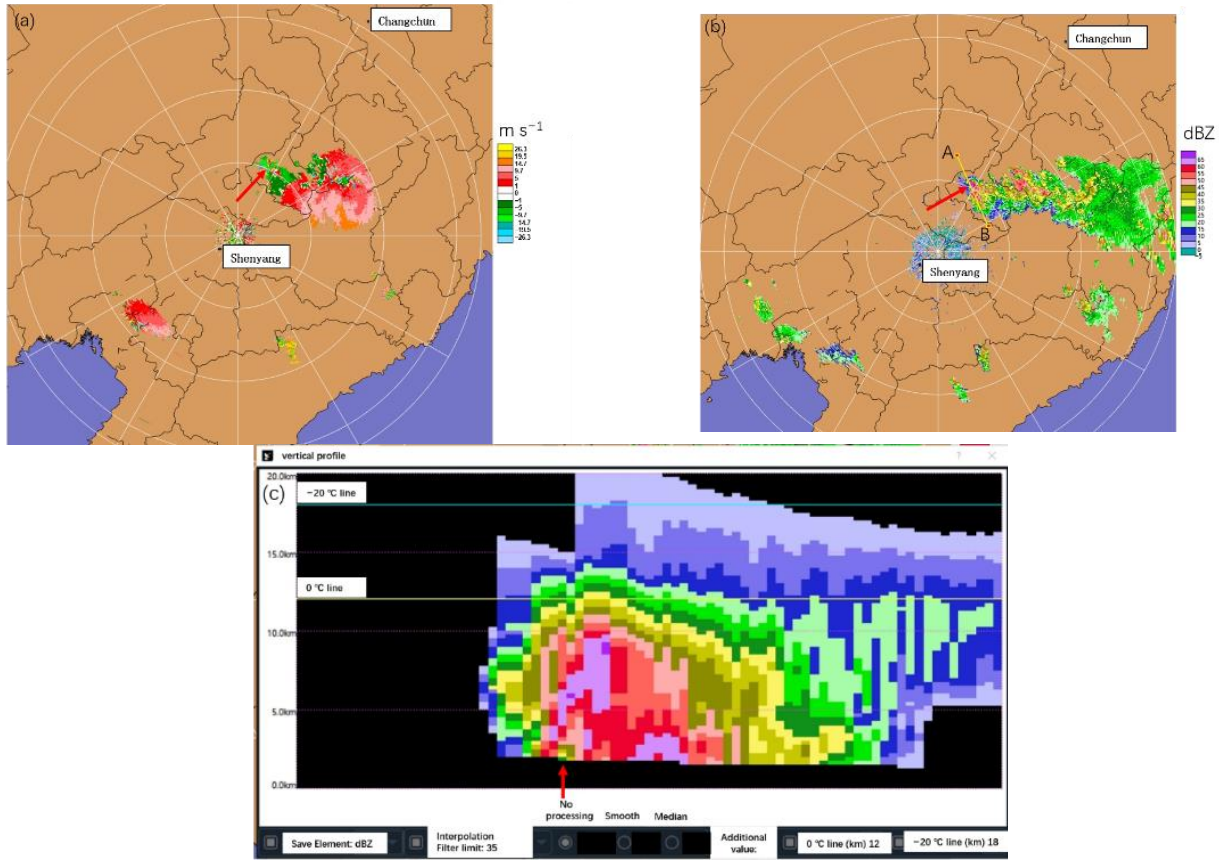

Figure 4. (a) The $3.3^{\circ}$ elevation Doppler velocity at 17:27:58 LST. (b) The $0.5^{\circ}$ elevation reflectance at 17:22:30 LST. (c) Cross-section of reflectivity along line AB in Figure $4 \mathrm{~b}$. The color bar and unit are the same as in (b). of Shenyang Doppler radar on 3 July 2019. The red arrows point to where the tornado appeared.

\section{WPS Domain Configuration}

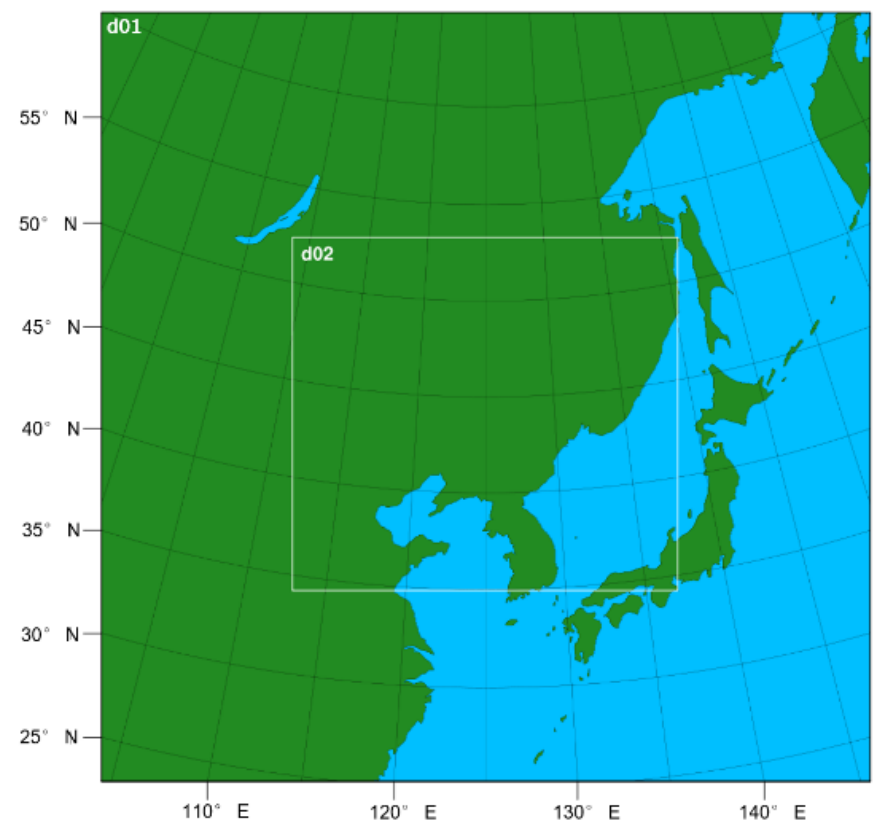

Figure 5. Two nested model domains (D01 and D02) and their horizontal resolutions (9 km and $3 \mathrm{~km}$, respectively).

Figure 6 shows the terrain of northeast China, with the main place names in the article shown. 


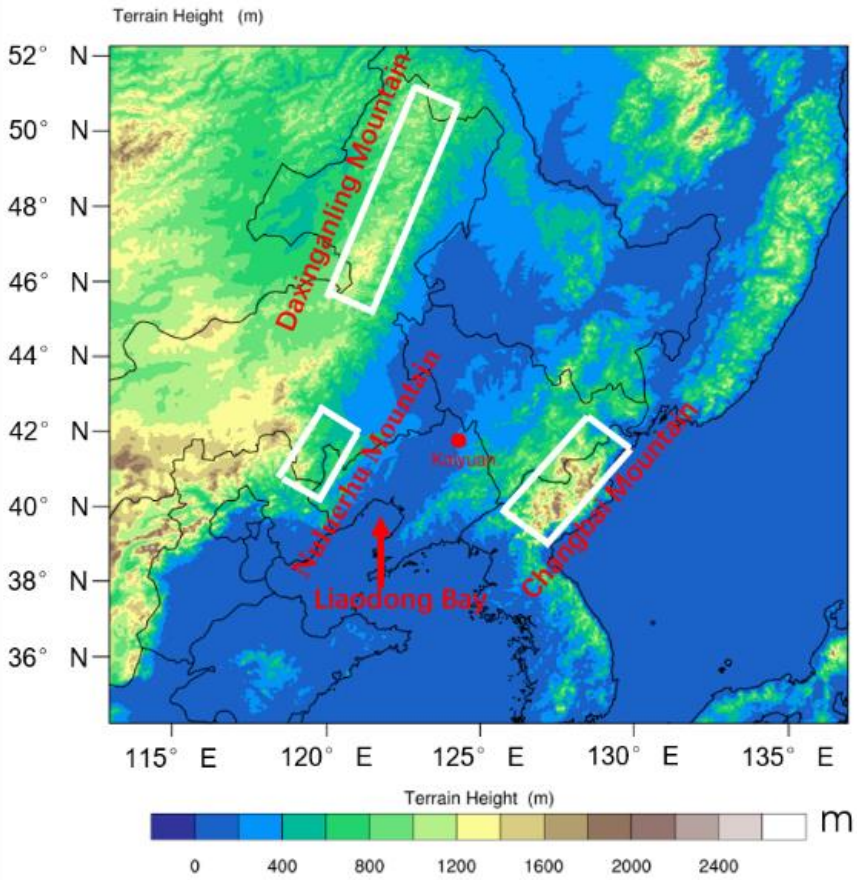

Figure 6. The terrain height (shaded; $m$ ) of Northeast China.

\section{Results}

\subsection{Analysis of Water Vapor Condition}

At 12:00 LST (Figure 7a) [26] on 3 July 2019, at $850 \mathrm{hPa}$, a $500 \mathrm{~km}$ long and $100 \mathrm{~km}$ wide northwest-southeast water vapor divergence zone appeared in the northwest jet in western Jilin, with a maximum of $8 \mathrm{~g} /\left(\mathrm{cm}^{2} \cdot \mathrm{hPa} \cdot \mathrm{s}\right)$, indicating that the strong dry and cold air moved southeast along the northwest jet. At 17:00 LST (Figure 7b), the trough moved to eastern Heilongjiang, Jilin and the junction of Liaoning and central Jilin. In front of it, there was a water vapor convergence zone, distributed in an east-northeast belt, similar to the shape of the satellite picture, with its organization strengthened and the central strength increased. Several strong water vapor convergence centers were embedded among them, and the maximum was $-20 \mathrm{~g} /\left(\mathrm{cm}^{2} \cdot \mathrm{hPa} \cdot \mathrm{s}\right)$. On the northwest side, it was close to a water vapor divergence zone, its organizational structure was also strengthened, and the center was $12 \mathrm{~g} /\left(\mathrm{cm}^{2} \cdot \mathrm{hPa} \cdot \mathrm{s}\right)$.
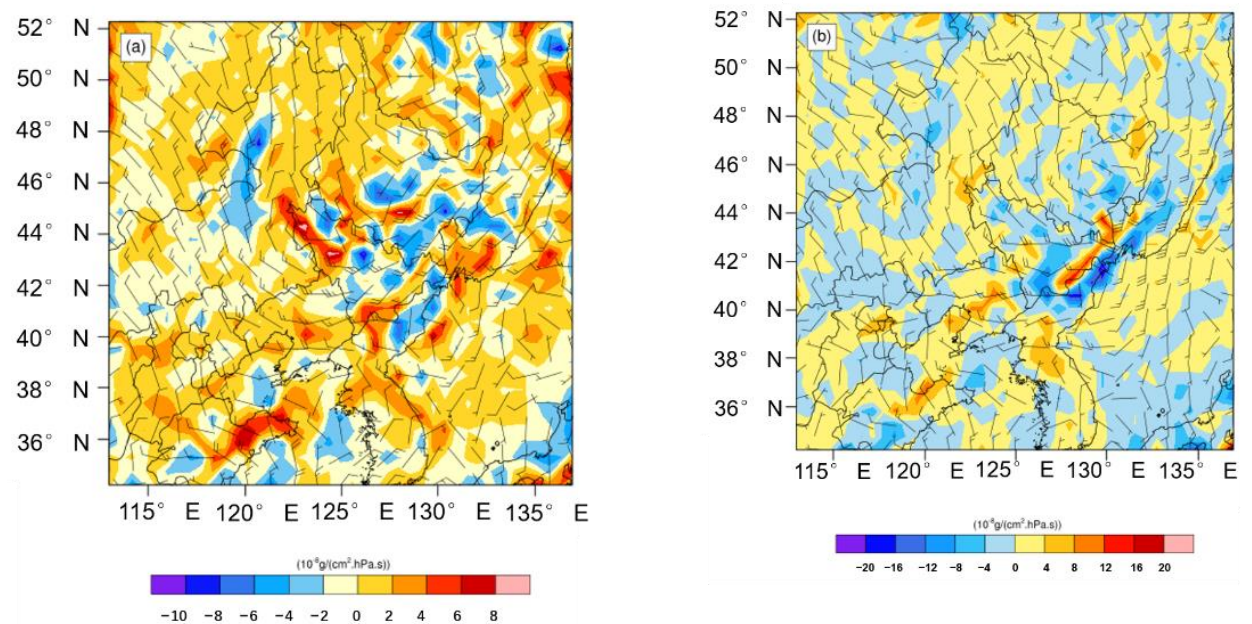

Figure 7. Horizontal winds (barbs; $\mathrm{m} \cdot \mathrm{s}^{-1}$ ) and water vapor flux divergence (shaded; $\left.10^{-8} \mathrm{~g} /\left(\mathrm{cm}^{2} \cdot \mathrm{hPa} \cdot \mathrm{s}\right)\right)$ at (a) 12:00 LST and (b) 17:00 LST at $850 \mathrm{hPa}$ in Domain 2 on 3 July 2019. A full bar is $4 \mathrm{~m} \cdot \mathrm{s}^{-1}$. 
At 11:00 LST, the relative humidity vertical profile in the zonal direction of $42.5^{\circ} \mathrm{N}$ (Figure 8a) [27] showed a high humidity zone between 115 and $134^{\circ} \mathrm{E}$, from west to east, with $700 \mathrm{hPa}$ as the center, which was larger than $80 \%$ between 124 and $134^{\circ}$ E. Between 115 and $128^{\circ} \mathrm{E}$, at $350-500 \mathrm{hPa}$, there was a dry area lower than $20 \%$, which intruded obliquely from west to the east and in places on the $700 \mathrm{hPa}$ high-humidity zone. Dry and cold air intruded with the northwest airflow from the west side of the northeast cold vortex. In the meridional direction along $124.0^{\circ} \mathrm{E}$ (Figure $8 \mathrm{~b}$ ), there was also a saturated water vapor zone centered at $700 \mathrm{hPa}$, with a humidity maximum larger than $80 \%$, two sinking dry columns placed above it; one was around $48^{\circ} \mathrm{N}$, and the humidity $30 \%$ sank to $500 \mathrm{hPa}$, another was between 38 and $42^{\circ} \mathrm{N}$, the humidity $10 \%$ sank from $200 \mathrm{hPa}$, and the humidity $20 \%$ reached $500 \mathrm{hPa}$. The convective system tilted from north to south with height, indicating that the dry air sank obliquely from south to north. In contrast to the satellite picture, the deep convective system appeared between 42 and $44^{\circ} \mathrm{N}$, there was a squall line on the southeast side of the northeast cold vortex, and the $48^{\circ} \mathrm{N}$ dry column in the north was caused by the intrusion of dry cold air from the northwest of the cold vortex, whereas the $38-42^{\circ} \mathrm{N}$ downdraft dry column was compensated for by the squall line and the updraft of deep convection in the southwest airflow in front of the upper trough. At 17:00 LST, Figure 8c shows that in the zonal direction of $42.5^{\circ} \mathrm{N}$, dry air sank at $200 \mathrm{hPa}$ approximately $125^{\circ}$ $\mathrm{E}$ west of the squall line, and the $50 \%$ column reached $250 \mathrm{hPa}$ at approximately $130^{\circ} \mathrm{E}$, corresponding to the squall line, and upper dry and cold air subsided west of the deep convection system. Figure $8 \mathrm{~d}$ shows that in the meridional direction of $124.0^{\circ} \mathrm{E}$, a $10 \%$ long and narrow dry air column dropped from 200 to $500 \mathrm{hPa}$ between 35 and $37^{\circ} \mathrm{N}$, and the $20 \%$ dry area extended northward to $42-43^{\circ}$ N. Over the next hour, the $10 \%$ column was discontinuous between $200 \mathrm{hPa}$ and $350 \mathrm{hPa}$.
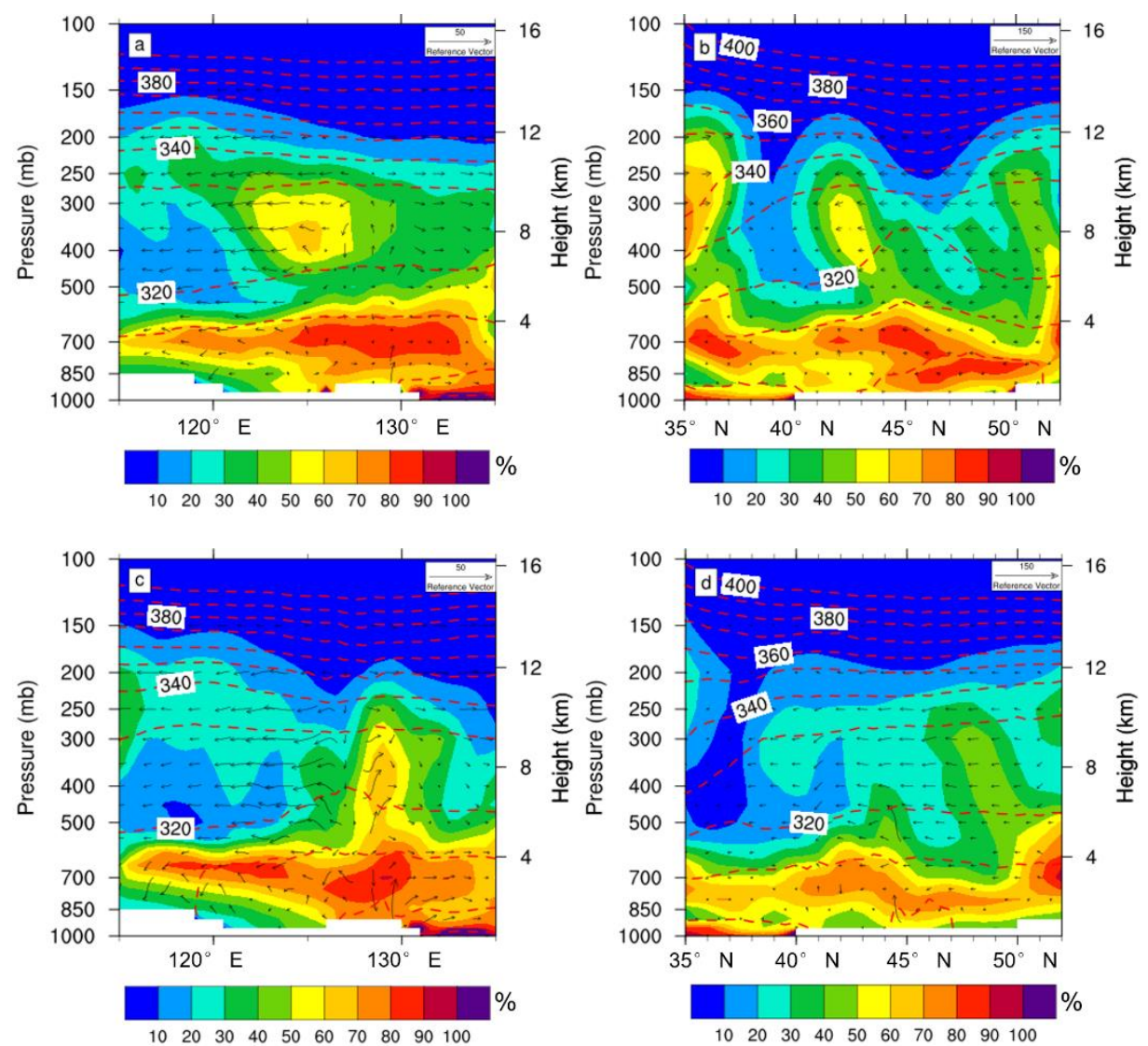

Figure 8. Vertical cross-section of relative humidity (shaded; \%), potential temperature (red contours), $\mathrm{uw} \times 50$ (vectored) along $42.5^{\circ} \mathrm{N}(\mathbf{a})$, and $124.0^{\circ} \mathrm{E}(\mathbf{b})$ at $11: 00 \mathrm{LST}$, along $42.5^{\circ} \mathrm{N}(\mathbf{c})$, and $124.0^{\circ} \mathrm{E}$ (d) at 17:00 LST on 3 July 2019 in Domain 2. 


\subsection{Dynamic Mechanism}

At 08:00 LST, Figure 9a shows that the vertical wind shear at $1000-3000 \mathrm{~m}$ in the southwest part of the northeast cold vortex was strengthening, the maximum at the junction of Jilin and Heilongjiang reached $16 \mathrm{~m} \cdot \mathrm{s}^{-1}$, and it extended to the southeast; the vorticity field was strengthening too, and the maximum in the positive vorticity zone in the southeast of the cold vortex was $24 \times 10^{-5} \mathrm{~s}^{-1}$. At 17:00 LST, Figure $9 \mathrm{~b}$ shows the vertical wind shear between 1000 and $3000 \mathrm{~m}$, which was strengthened by $18 \mathrm{~m} \cdot \mathrm{s}^{-1}$ west of the cold vortex, perhaps which was related to the terrain of Daxinganling. The northeast-southwest high vertical shear zone in the southeast of the cold vortex with the maximum was $16 \mathrm{~m} \cdot \mathrm{s}^{-1}$, which was related to the barrier of Changbai Mountain in the west of the subtropical high. A squall line was formed between it and another vertical shear zone to the south-southeast of the cold vortex. Due to the extrusion of Nuluerhu Mountain, a northeast-southwest $14 \mathrm{~m} \cdot \mathrm{s}^{-1}$ high vertical wind shear zone appeared in southwestern Liaoning. The junction between them was the smallest vertical shear, where the tornado occurred. The supercell generated in the front right was related to the upper trough of $700 \mathrm{hPa}$ and above; the lowest TBB, $-57^{\circ} \mathrm{C}$, was concentrated in the west part, which was proof of the prevailing afternoon valley wind, as well as the sea and land breeze between Liaodong Bay and the land. The three mountain areas are sunny and hot during the daytime, which strengthens convection in the mountain area, and the flat airflow is transported to the mountain area which strengthen the vertical wind shear there. The smallest vertical wind shear center of $4 \mathrm{~m} \cdot \mathrm{s}^{-1}$ still existed at the central junction of Liaoning and Jilin. The secondary circulation was downdraft; therefore, the supercell north of Liaodong Bay was completely separated from the squall line southeast of the cold vortex.
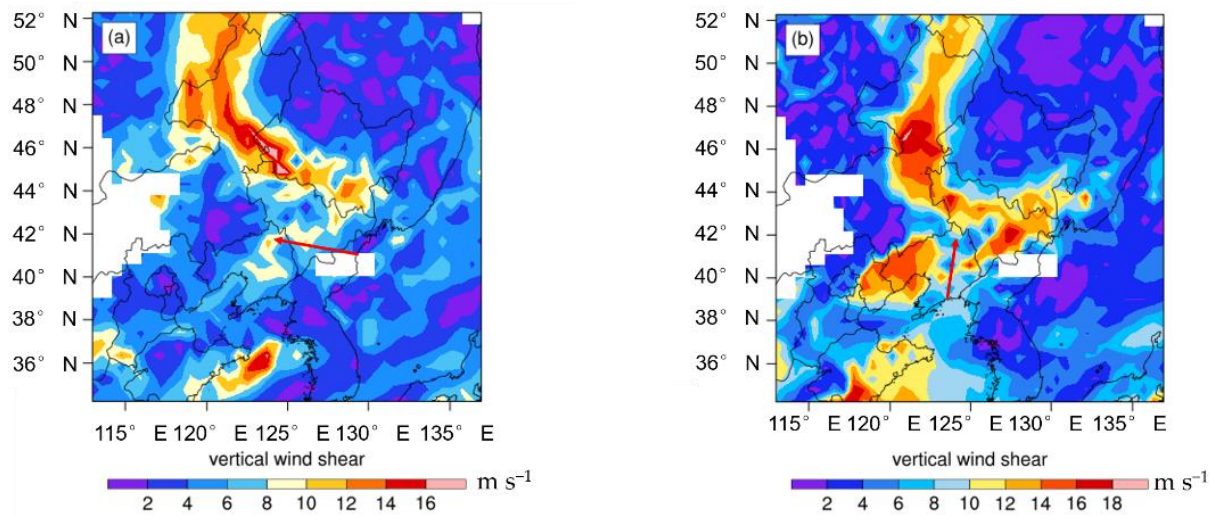

Figure 9. Vertical wind shear between 1000 and $3000 \mathrm{~m}\left(\mathrm{~m} \cdot \mathrm{s}^{-1}\right)$ at (a) 08:00 LST; (b) 17:00 LST in Domain 2 on 3 July 2019.

Figure 10a shows that at 17:00 LST, in the $850 \mathrm{hPa}$ divergence field, in the southeast of the cold vortex, a NE-SW-oriented convergence zone appeared from eastern Heilongjiang to eastern Jilin, and a divergence zone was close to it in the southeast. There was a NESW-oriented convergence zone in central Liaoning. There was a divergence zone with a $-15 \times 10^{-5} \mathrm{~s}^{-1}$ minimum core between the two convergence zones. They coupled with each other well. The satellite pictures (Figure 3) show that the north side of the squall line was very smooth, which was perhaps related to the dry and cold air intruded from the northwest of the cold vortex, sinking and divergent airflow. Figure 10b shows that in the $850 \mathrm{hPa}$ vorticity field, there was a $-5 \times 10^{-5} \mathrm{~s}^{-1}$ negative vorticity center at the middle junction of Liaoning and Jilin, which was surrounded by positive vorticity zones. Figure 10c shows that in the $850 \mathrm{hPa}$ vertical velocity field, there was a positive center of $0.2 \mathrm{~m} / \mathrm{s}$ and a negative vertical velocity of $-0.4 \mathrm{~m} \cdot \mathrm{s}^{-1}$ near Kaiyuan. 

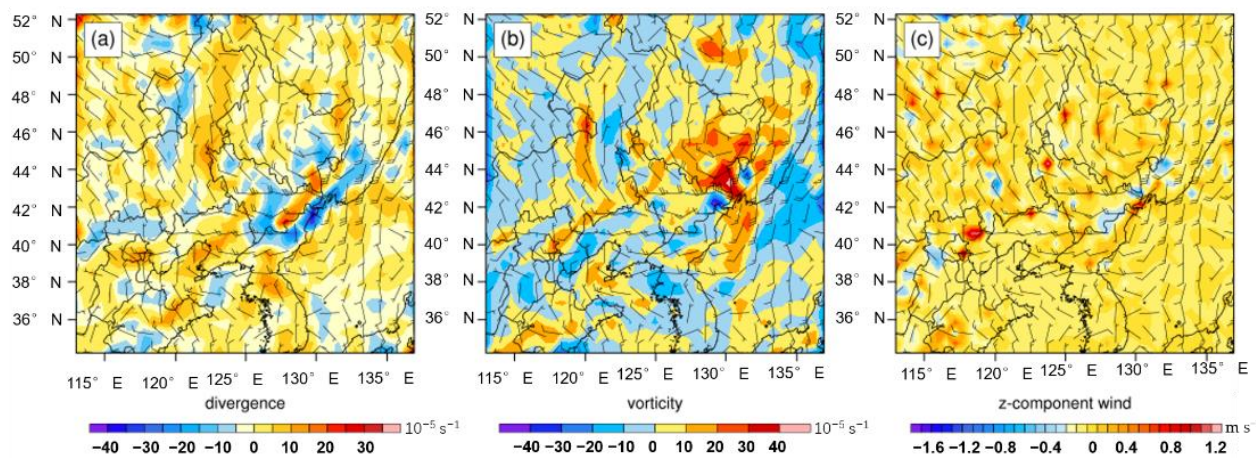

Figure 10. Horizontal winds and (a) divergence $\left(10^{-5} \mathrm{~s}^{-1}\right)$, (b) vorticity $\left(10^{-5} \mathrm{~s}^{-1}\right)$, (c) vertical velocity $\left(\mathrm{m} \cdot \mathrm{s}^{-1}\right)$ at $850 \mathrm{hPa}$ at 17:00 LST in Domain 2 on 3 July 2019. A full bar is $4 \mathrm{~m} \cdot \mathrm{s}^{-1}$.

Figure $11 \mathrm{a}, \mathrm{c}$ shows the vertical cross-section of $\mathrm{w}(\mathrm{u})$ along $42.5^{\circ} \mathrm{N}$, Figure $11 \mathrm{~b}, \mathrm{~d}$ shows the vertical cross-section of $\mathrm{w}(\mathrm{v})$ along $124.0^{\circ} \mathrm{E}$ at 17:00 LST. Figure 11a shows that between 129 and $130^{\circ} \mathrm{E}$, a $0.15 \mathrm{~m} \cdot \mathrm{s}^{-1}$ rising center appeared at a height of $400-500 \mathrm{hPa}$. At $700-850 \mathrm{hPa}, 121-124^{\circ} \mathrm{E}$, there was a $0.1 \mathrm{~m} \cdot \mathrm{s}^{-1}$ rising center. Figure $11 \mathrm{~b}$ shows that at $500-850 \mathrm{hPa}, 43-45^{\circ} \mathrm{N}$, there was a rising motion column, with a center of $0.35 \mathrm{~m} \cdot \mathrm{s}^{-1}$ at $600 \mathrm{hPa}$. Figure $11 \mathrm{c}$ shows that between 123 and $130^{\circ} \mathrm{E}$, the westerly gale core subsided from the upper troposphere, a $20 \mathrm{~m} \cdot \mathrm{s}^{-1}$ gale core sank from 200 to $400 \mathrm{hPa}$ between 126 and $127^{\circ} \mathrm{E}$, a $10 \mathrm{~m} \cdot \mathrm{s}^{-1}$ isoline sank to $800 \mathrm{hPa}$ between 123 and $129^{\circ} \mathrm{E}$, and in the east there was a low level below $850 \mathrm{hPa}$. Figure $11 \mathrm{~d}$ shows that the $-27 \mathrm{~m} \cdot \mathrm{s}^{-1}$ gale core was between 43 and $46^{\circ} \mathrm{N}$ and at 250-350 hPa. At approximately $42.5^{\circ} \mathrm{N}$, the $-10 \mathrm{~m} \cdot \mathrm{s}^{-1}$ north isoline reached $650 \mathrm{hPa}$. There was a $5 \mathrm{~m} \cdot \mathrm{s}^{-1}$ wind center below $800 \mathrm{hPa}$ at approximately $40^{\circ} \mathrm{N}$.
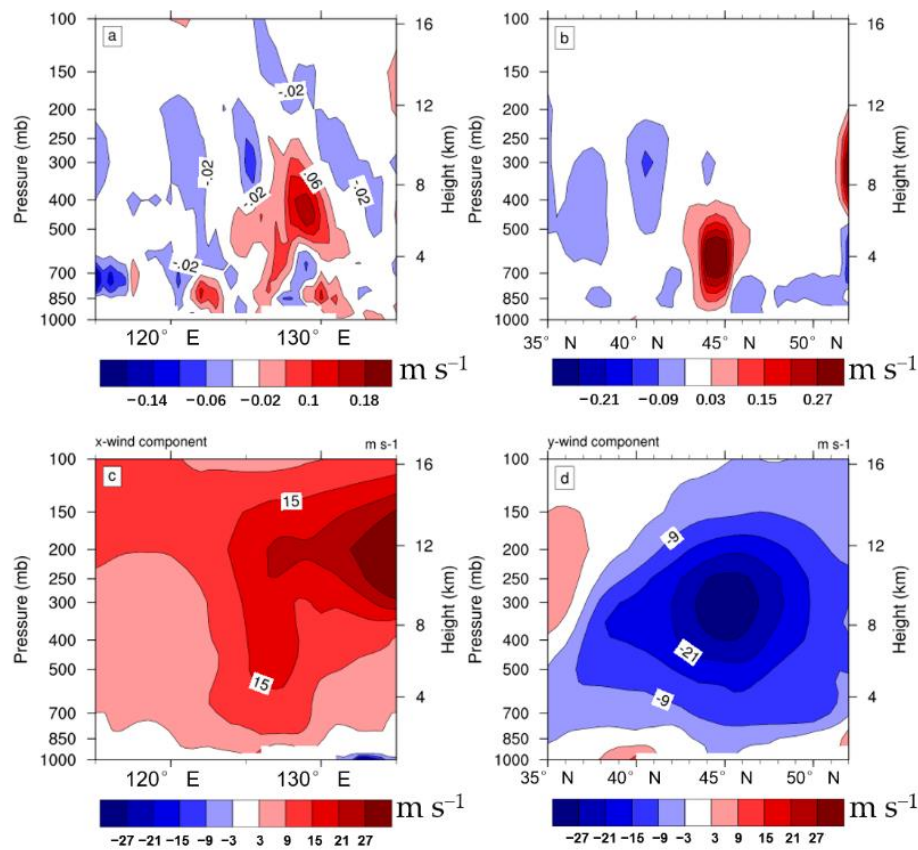

Figure 11. Vertical cross-section of $\mathrm{w}$ (shaded; $\mathrm{m} \cdot \mathrm{s}^{-1}$ ) along $42.5^{\circ} \mathrm{N}(\mathbf{a})$ and $124.0^{\circ} \mathrm{E}(\mathbf{b})$; vertical cross-section of $\mathrm{u}$ (shaded; $\mathrm{m} \cdot \mathrm{s}^{-1}$ ) along $42.5^{\circ} \mathrm{N}(\mathrm{c})$; and $\mathrm{v}$ (shaded; $\mathrm{m} \cdot \mathrm{s}^{-1}$ ) along $124.0^{\circ} \mathrm{E}(\mathrm{d})$ at 17:00 LST in Domain 2 on 3 July 2019.

The meridional vertical profiles of vorticity and vw $\left({ }^{*} 50\right)$ resultant wind (Plume) along $124.0^{\circ} \mathrm{E}$ show that, at 03:10 LST (Figure 12a), there was a positive vorticity column between 42 and $44^{\circ} \mathrm{N}$, at $600-1000 \mathrm{hPa}$, with the $15 \times 10^{-5} \mathrm{~s}^{-1}$ center of $850-700 \mathrm{hPa}$, approximately $43.5^{\circ} \mathrm{N}$. The positive vorticity center with a high value above $550 \mathrm{hPa}$ moved southward and sank, between 43 and $48^{\circ} \mathrm{N}$, with $30 \times 10^{-5} \mathrm{~s}^{-1}$ center at 250-350 hPa. At 17:00 
LST (Figure 12b), between 42.5 and $43.5^{\circ} \mathrm{N}$ and below $850 \mathrm{hPa}$, there was a positive vorticity column with a center value of $10 \times 10^{-5} \mathrm{~s}^{-1}$, and there were several negative vorticity columns above it, left and right coupled with it together. Between 44 and $49^{\circ} \mathrm{N}$, below $450 \mathrm{hPa}$, there was a positive vorticity column sink, with the $15 \times 10^{-5} \mathrm{~s}^{-1}$ center at $600-750 \mathrm{hPa}$ at approximately $45^{\circ} \mathrm{N}$, which is related to the sinking northeast cold vortex, indicating that the cold vortex drops down to a low level. The zonal vertical profiles of vorticity and $\mathrm{u}, \mathrm{w}^{*} 50$ resultant wind (Plume) along $42.5^{\circ} \mathrm{N}$ show that, at 10:00 LST (Figure 12c), there was a $5 \times 10^{-5} \mathrm{~s}^{-1}$ positive vorticity column at $122-125^{\circ} \mathrm{E}$ from a low level to $700 \mathrm{hPa}$. At 17:00 LST (Figure 12d), between 125 and $127^{\circ} \mathrm{E}$, a positive vorticity column sank at $200-500 \mathrm{hPa}$, the center increased to $30 \times 10^{-5} \mathrm{~s}^{-1}$ near $300 \mathrm{hPa}$, and there was a negative vorticity column on the north side; at $250-400 \mathrm{hPa}$, its center was $-10 \times 10^{-5} \mathrm{~s}^{-1}$. Between 122 and $123^{\circ} \mathrm{E}$, the inclined vorticity column reached $650 \mathrm{hPa}$ with a $10 \times 10^{-5} \mathrm{~s}^{-1}$ center near the surface.
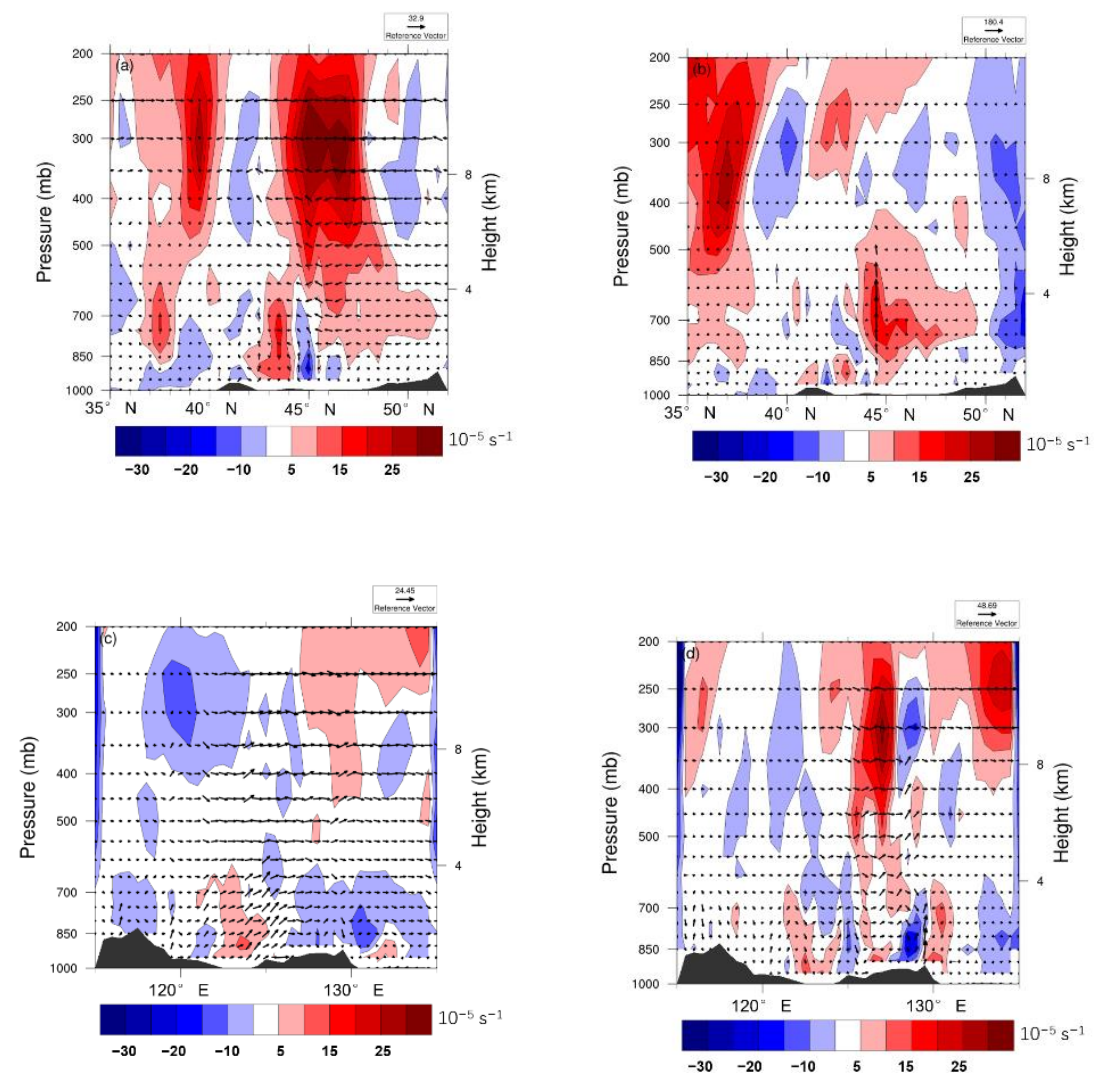

Figure 12. Vertical profile of the resultant wind (Plume): (a,c) along longitude $124.0^{\circ} \mathrm{E}, \mathrm{v}$ at 10:00 LST; (b,d) along latitudinal $42.5^{\circ} \mathrm{N}$ vorticity (shaded, unit: $10^{-5} \mathrm{~s}^{-1}$ ), $\mathrm{u}$ at 17:00 LST and $\mathrm{w}^{*} 50$ (arrows; $\mathrm{m} \cdot \mathrm{s}^{-1}$ ) in Domain 2 on 3 July 2019.

\subsection{Thermal and Instability Characteristics}

$\theta_{\text {se }}$ zonal vertical profiles along $42.5^{\circ} \mathrm{N}$ show that the $316 \mathrm{~K}$ low value belt was at $600 \mathrm{hPa}$, at 10:00 LST, including a $316 \mathrm{~K}$ small center between 121 and $124^{\circ} \mathrm{E}$; subsequently, the $316 \mathrm{~K}$ center expanded and moved slowly eastward. At 17:00 LST, Figure 13a shows that the $316 \mathrm{~K} \theta_{\text {se }}$ low zone was near $600 \mathrm{hPa}$, east of $118^{\circ} \mathrm{E}$; the lower level was a convective instability zone, with a low center between 125 and $127^{\circ} \mathrm{E}$ at $550-700 \mathrm{hPa}$; and the specific humidity was $3 \mathrm{~g} / \mathrm{kg}$ at $600 \mathrm{hPa}$ between 122 and $123^{\circ}$ E. $\theta_{\text {se }}$ meridional vertical profiles along $124.0^{\circ} \mathrm{E}$ show that at $02: 20 \mathrm{LST}$, the $316 \mathrm{~K}$ center was north of $45^{\circ} \mathrm{N}, \theta_{\text {se }}$ was $324 \mathrm{~K}$ at the ground near $42.5^{\circ} \mathrm{N}$, and then, subsequently, the $316 \mathrm{~K} \theta_{\text {se }}$ low center moved southward. At 03:13 LST, the $316 \mathrm{~K} \theta_{\text {se }}$ center reached $42^{\circ} \mathrm{N}$ at $600 \mathrm{hPa}$, and $\theta_{\text {se }}$ at the ground between 40 and $43^{\circ} \mathrm{N}$ increased to $332 \mathrm{~K}$. However, over the next hour, the $316 \mathrm{~K}$ center disappeared. At 17:00 LST, Figure 13b shows that the $320 \mathrm{~K}$ low value center belt was at $500-700 \mathrm{hPa}$, 
the low level $\theta_{\text {se }}$ at $40-45^{\circ} \mathrm{N}$ was larger than both sides, and $320 \mathrm{~K}$ rose to $700 \mathrm{hPa}$. The specific humidity at approximately $650 \mathrm{hPa}$ was up to $3 \mathrm{~g} / \mathrm{kg}$.
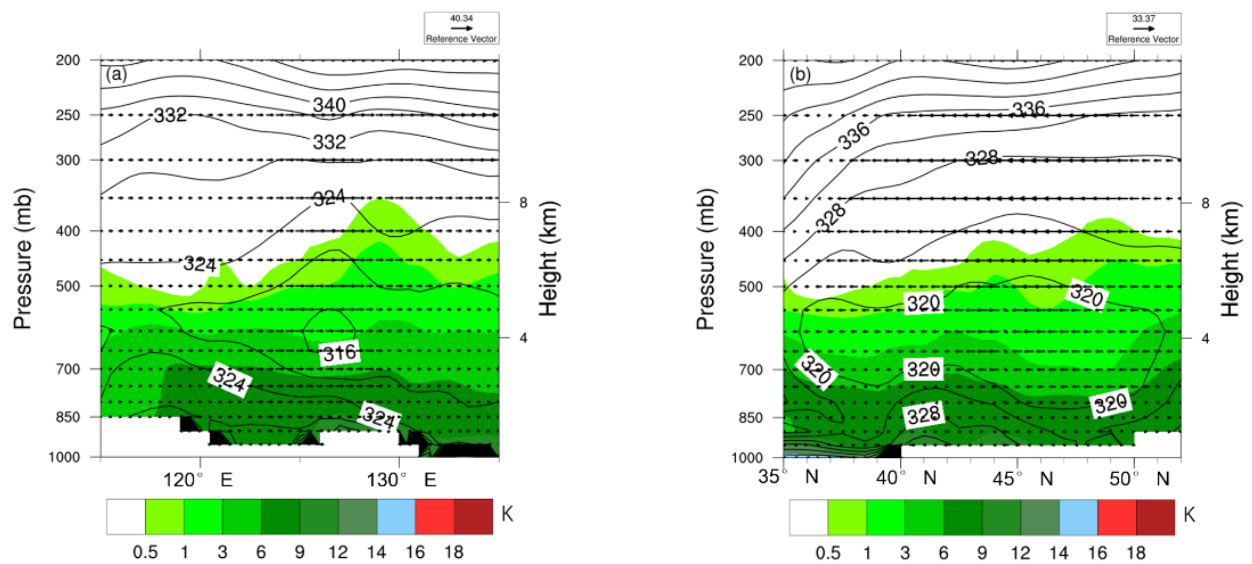

Figure 13. Vertical cross-section of pseudo-equivalent potential temperature (solid line; K) and specific humidity (shaded; $\mathrm{g} / \mathrm{kg}$ ) and uw (arrows; $\mathrm{m} \cdot \mathrm{s}^{-1}$ ) along $42.5^{\circ} \mathrm{N}\left(\right.$ a) and $\mathrm{vw}$ (arrows; $\mathrm{m} \cdot \mathrm{s}^{-1}$ along $124.0^{\circ} \mathrm{E}(\mathbf{b})$ in Domain 2 at 17:00 LST on 3 July 2019.

Kaiyuan station sounding T-lnp diagrams on 3 July 2019 based on the WRF simulation data and Kaiyuan surface meteorological observation station display showed that the convective available potential energy (CAPE) was $29.9 \mathrm{~J} / \mathrm{kg}$ at 08:00 LST (Table 1), after which, perhaps due to the influence of solar radiation heating, it increased rapidly, to $1137.7 \mathrm{~J} / \mathrm{kg}$ at 11:00 LST, then $2305.7 \mathrm{~J} / \mathrm{kg}$ at 14:00 LST; Figure 14 shows that CAPE was $2394.1 \mathrm{~J} / \mathrm{kg}$ at 17:00 LST, although suddenly decreased to $0 \mathrm{~J} / \mathrm{kg}$ at 18:00 LST.

Table 1. The modified sounding T-lnp physical quantity table of Kaiyuan station.

\begin{tabular}{cccccc}
\hline Time (LST) & $\mathbf{0 3 : 0 8}$ & $\mathbf{0 3 : 1 1}$ & $\mathbf{0 3 : 1 4}$ & $\mathbf{0 3 : 1 7}$ & $\mathbf{0 3 : 1 8}$ \\
\hline CAPE (J/kg) & 29.9 & 1137.5 & 2305.7 & 2394.1 & 0.0 \\
CIN (J/kg) & 178.2 & 27.0 & 105.1 & 15.5 & 0.0 \\
SHR 0-3 (m/s) & 11.5 & 9.3 & 14.6 & 17.2 & 37.1 \\
LCL (m) & 1337 & 1387.4 & 1341.4 & 1047.0 & 292.7 \\
\hline
\end{tabular}

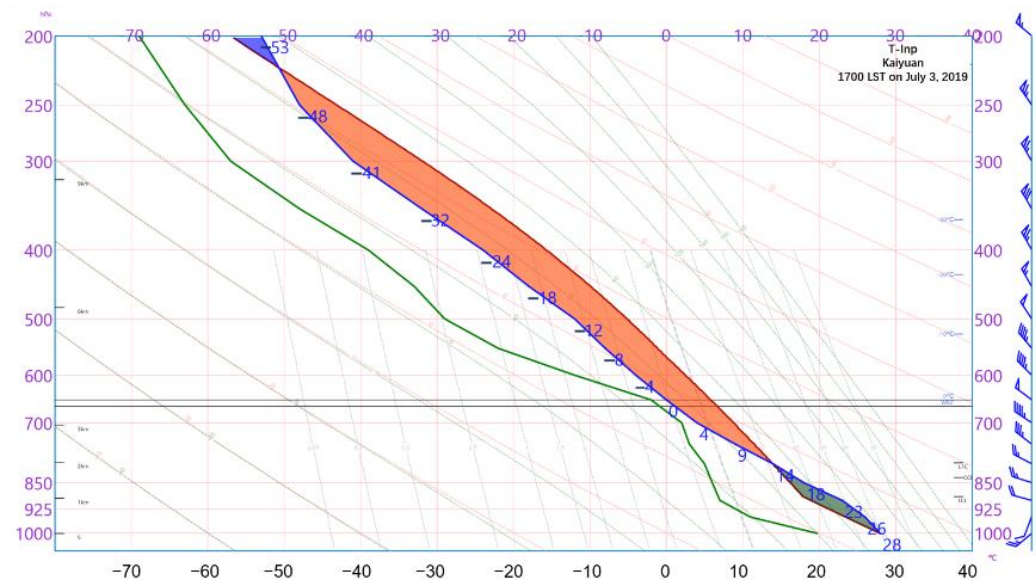

Figure 14. The 17:00 LST Kaiyuan T-lnp from the WRF simulations in Domain 2 and surface observations. A full bar is $4 \mathrm{~m} \cdot \mathrm{s}^{-1}$.

Convective inhibition (CIN) was $178.2 \mathrm{~J} / \mathrm{kg}$ at 08:00 LST, $27.0 \mathrm{~J} / \mathrm{kg}$ at 11:00 LST, $105.1 \mathrm{~J} / \mathrm{kg}$ at 14:00 LST, $15.5 \mathrm{~J} / \mathrm{kg}$ at 17:00 LST, and $0 \mathrm{~J} / \mathrm{kg}$ at 18:00 LST.

The $0-3 \mathrm{~km}$ vertical wind shear was $11.5 \mathrm{~m} \cdot \mathrm{s}^{-1}$ at 08:00 LST, $9.3 \mathrm{~m} \cdot \mathrm{s}^{-1}$ at 11:00 LST, and $14.6 \mathrm{~m} \cdot \mathrm{s}^{-1}$ at 14:00 LST. At 17:00 LST, the wind was $17 \mathrm{~m} \cdot \mathrm{s}^{-1}$ northwest at $700 \mathrm{hPa}$, 
$9.7 \mathrm{~m} \cdot \mathrm{s}^{-1}$ southwest at the surface, and $17.2 \mathrm{~m} \cdot \mathrm{s}^{-1}$ vertical wind shear at $0-3 \mathrm{~km}$. By the next hour, $700 \mathrm{hPa}$ wind had reduced to $14 \mathrm{~m} \cdot \mathrm{s}^{-1}$, whereas the surface wind had turned southeast at $23 \mathrm{~m} \cdot \mathrm{s}^{-1}$, and the $0-3 \mathrm{~km}$ vertical wind shear was $37.1 \mathrm{~m} \cdot \mathrm{s}^{-1}$. The lifting condensation level (LCL) was $1337 \mathrm{~m}$ at 08:00 LST, and decreased gradually in the afternoon, to $1047 \mathrm{~m}$ at 17:00 LST and 292.7 $\mathrm{m}$ 18:00 LST. The $2{ }^{\circ} \mathrm{C}$ low center of T- $\mathrm{T}_{\mathrm{d}}$ was around the height of $700 \mathrm{hPa}$ from 08:00 to $1800 \mathrm{LST}$.

The hodographs show that, at 08:00 LST, the wind direction above $700 \mathrm{hPa}$ was northwest, whereas it was southwest below $700 \mathrm{hPa}$; the turning height was $700 \mathrm{hPa}$. Subsequently, Figure 15 shows that at 17:00 LST, the turning height dropped to $950 \mathrm{hPa}$; above was northwest, whereas below was southwest. Near the surface, the winds veered with height from west-southeasterly to southerly, creating strong shear within $1 \mathrm{~km}$ of the lower troposphere $\left(8.07 \mathrm{~m} \cdot \mathrm{s}^{-1}\right)$.

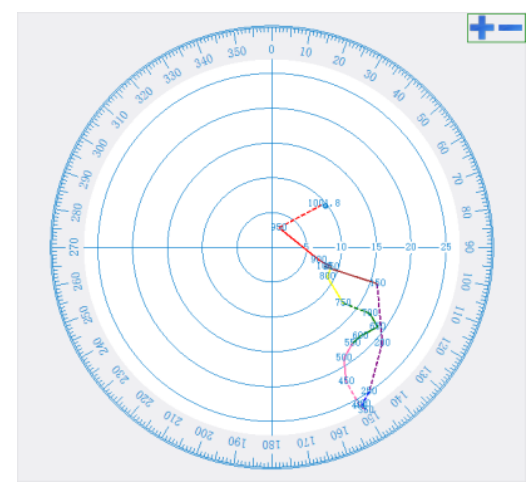

Figure 15. The 17:00 LST Kaiyuan hodograph from the WRF simulations in Domain 2 and surface data.

\section{Conclusions}

Due to the obstruction of the subtropical high, the northeast cold vortex persisted for a long time. Under the action of the inclination of the warm ridge in the west, a cutoff cold vortex, stepped troughs and weak low pressure on the ground formed. The upper cold vortex fell southward, the upper trough passed through, and the inverted surface trough were the main weather situation characteristics of the Kaiyuan tornado.

The upper-level cold vortex falling south caused the middle and upper-level cold air to move southward and sink with positive vorticity. Dry and cold air intruded from the west and north and interacted with the warm and wet air, thus forming convective instability.

The water vapor saturation layer at $700 \mathrm{hPa}$ was conducive to the formation of shallow clouds at the middle and low layers and the penetration of solar shortwave radiation into the ground during the daytime, but was not conducive to the emission of longwave ground radiation. In addition, the transportation of warm advection from the high-temperature area of Hebei was conducive to the rapid increase in CAPE.

Due to the warming of solar radiation during the daytime, the convective activities in the three mountainous areas of Changbai Mountain, Daxinganling Mountain, and Nuluerhu Mountain were strengthened during the daytime, which was conducive to the formation of vertical wind shear zones in the northwest, southeast, and southwest directions. The convective activity on Changbai Mountain strengthened the convective activity of the squall line and the water vapor convergence zone south of the squall line. The southward movement of the northeast cold vortex strengthened the water vapor divergence on the north side of the squall line, and the squall line extended westward after strengthening. Sea and land breezes caused the formation of the supercell north of Liaodong Bay and the sinking circulation of dry air. The tail of the squall line and supercell jointly provided strong southeast wind outflow on the surface layer. When the northeast cold vortex moved southward, the sinking dry and cold northwest air flow from the upper level was superimposed on it; thus, the height of strong vertical wind shear was reduced, 
resulting in strong vertical wind shear near the ground, which triggered the formation of a tornado.

Author Contributions: Y.W. initiated the study and performed the analysis of meteorological conditions, numerical simulation, dynamic diagnosis and analysis; wrote the original draft. T.W. contributed to full-text discussion, checking and proofreading. P.Y. contributed to Doppler radar picture analysis; W.X. contributed to some dynamic diagnosis and analysis. All authors have read and agreed to the published version of the manuscript.

Funding: This work was funded by the National Key Research and Development Program of China. (Grant No. 2018YFC1507301).

Institutional Review Board Statement: Ethical review and approval are waived for this study, because it does not involve humans or animals.

Informed Consent Statement: Patient consent was not applicable, because this study did not involve humans.

Data Availability Statement: The data presented in this study are available on request from the corresponding author. The amount of data is very large, the data are not publicly available.

Acknowledgments: We thank to the China Meteorological Administration for providing surface, sounding observation data, hourly precipitation observation data, and Doppler radar data. NCAR for providing NCEP reanalysis data, WRF version 4.0 mesoscale numerical prediction model and NCL mapping software, Kochi University of Japan for providing hmw-8 cloud images. We are grateful to the High-Performance Computing Center (HPCC) of Nanjing University for performing the numerical calculations in this paper on its blade cluster system.

Conflicts of Interest: The authors declare no conflict of interest.

\section{References}

1. Wang, X.; Yu, X.; Zhou, X. Study of Northeast China torandoes: The environmental characteristics. Acta Meteorol. Sin. 2015, 73, 425-441. (In Chinese)

2. $\quad$ Davies-Jones, R.; Trapp, R.; Bluestein, I.I. Tornadoes and tornadic storms. In Severe Convective Storms; Doswell, C.A., III, Ed.; American Meteorological Society: Boston, MA, USA, 2001; pp. 167-221.

3. Trapp, R.; Stumpf, G.; Manross, K. A reassessment of the percentage of tornadic mesocyclones. Weather Forecast. 2005, 20, 680-687. [CrossRef]

4. Yu, X.; Zhou, X.; Wang, X. The advances in the nowcasting techniques on thunderstorms and severe convection. Acta Meteorol. Sin. 2012, 70, 311-317. (In Chinese)

5. Brooks, I.I.; Lee, J.; Craven, J. The spatial distribution of severe thunderstorm and tornado enviroments from global reanalysis data. Atmos. Res. 2003, 67-68, 73-94. [CrossRef]

6. Markowski, P.M.; Straka, J.M.; Rasmussen, E.N. Direct Surface Thermodynamic Observations within the Rear-Flank Downdrafts of Nontornadic and Tornadic Supercells. Mon. Weather Rev. 2002, 130, 1692-1721. [CrossRef]

7. Yu, X.D.; Zheng, Y.Y.; Zhang, A.M.; Yao, Y.Q.; Fang, C. The Detection of a Severe Tornado Event in Anhui with China New Generation Weather Radar. Plat. Meteorol. 2006, 25, 914-924. (In Chinese)

8. Lewellen, D.; Xia, J. The influence of a local swirl ratio on tornado intensification near the surface. J. Atmos. Sci. 2000, 57, 527-544. [CrossRef]

9. Zhang, L.; Sun, J.; Ying, Z.; Xiao, X. Initiation and development of a squall line crossing Hangzhou Bay. J. Geophys. Res. Atmos. 2021, 126, e2020JD032504. [CrossRef]

10. Sun, Z.; Xue, M.; Zhu, K.; Zhou, B. Prediction of EF4 supercell tornado in Funing, China: Resolution dependency of simulated tornadoes and their structures. Atmos. Res. 2019, 229, 175-189. [CrossRef]

11. Xue, M.; Zhao, K.; Wang, M.; Li, Z.; Zheng, Y. Recent significant tornadoes in China. Adv. Atmos. Sci. 2016, 33, 1209-1217. [CrossRef]

12. Xue, M.; Hu, M.; Schenkman, A. Numerical Prediction of the 8 May 2003 Oklahoma City Tornadic Supercell and Embedded Tornado Using ARPS with the Assimilation of WSR-88D Data. Weather Forecast. 2014, 29, 39-62. [CrossRef]

13. Wurman, J. The Multiple-Vortex Structure of a Tornado. Weather Forecast. 2002, 17, 473-505. [CrossRef]

14. Trapp, R.J.; Mitchell, E.D.; Tipton, G.A.; Effertz, D.W.; Watson, A.I.; Andra, D.L., Jr.; Magsig, M.A. Descending and Nondescending Tornadic Vortex Signatures Detected by WSR-88Ds. Weather Forecast. 1999, 14, 625-639. [CrossRef]

15. Snook, N.; Xue, M.; Jung, Y. Tornado-Resolving Ensemble and Probabilistic Predictions of the 20 May 2013 Newcastle-Moore EF5 Tornado. Mon. Weather Rev. 2019, 147, 1215-1235. [CrossRef] 
16. Schenkman, A.; Xue, M.; Hu, M. Tornadogenesis in a High-Resolution Simulation of the 8 May 2003 Oklahoma City Supercell. J. Atmos. Sci. 2014, 71, 130-154. [CrossRef]

17. Schenkman, A.; Xue, M.; Shapiro, A. Tornadogenesis in a Simulated Mesovortex within a Mesoscale Convective System. J. Atmos. Sci. 2012, 69, 3372-3390. [CrossRef]

18. Rotunno, R.; Bryan, G.H.; Nolan, D.S.; Dahl, N.A. Axisymmetric Tornado Simulations at High Reynolds Number. J. Atmos. Sci. 2016, 73, 3843-3854. [CrossRef]

19. Roberts, B.; Xue, M.; Schenkman, A.D.; Dawson, D.T. The Role of Surface Drag in Tornadogenesis within an Idealized Supercell Simulation. J. Atmos. Sci. 2016, 73, 3371-3395. [CrossRef]

20. Mashiko, W.; Niino, H.; Kato, T. Numerical Simulation of Tornadogenesis in an Outer-Rainband Minisupercell of Typhoon Shanshan on 17 September 2006. Mon. Weather Rev. 2009, 13, 4238-4260. [CrossRef]

21. Mashiko, W. A Numerical Study of the 6 May 2012 Tsukuba City Supercell Tornado. Part II: Mechanisms of Tornadogenesis. Mon. Weather Rev. 2016, 144, 3077-3097. [CrossRef]

22. Tao, T.; Tamura, T. Numerical Study of the 6 May 2012 Tsukuba Supercell Tornado: Vorticity Sources Responsible for Tornadogenesis. Mon. Weathet Rev. 2020, 148, 1205-1228. [CrossRef]

23. Zhang, T.; Guan, L.; Zheng, Y.G. Damage survey of the 3 July 2019 Kaiyuan tornado in Liaoning Province and its evolution revealed by disaster. Meterol. Mon. 2020, 46, 603-617. (In Chinese)

24. Yan, Q.; Zhang, A.; Shen, L.; Cui, J.; Zhao, Z. Observational Analysis of tornado in Kaiyuan of 2019. J. Catas. 2021, 36, 112-116. (In Chinese)

25. Skamarock, W.C.; Klemp, J.B.; Dudhia, J.; Gill, D.O.; Barker, D.M.; Wang, W.; Powers, J.G. A Description of the Advanced Research WRF Version 3; Ncar Tchnical Note, NCAR/TN-475+STR; Natioanal Center for Atmospheric Research: Boulder, CO, USA, 2008

26. Wang, Y.; Wang, T. Numerical Simulation of a Heavy Rainstorm in Northeast China Caused by the Residual Vortex of Typhoon 1909 (Lekima). Atmosphere 2021, 12, 120. [CrossRef]

27. Heo, K.Y.; Kim, K.E.; Ha, K.J.; Park, K.S.; Jun, K.C.; Shim, J.S.; Suh, Y.S. Simulation of snowstorm over the Yellow Sea using a mesoscale coupled model. Asia-Pac. J. Atmos. Sci. 2010, 46, 437-452. [CrossRef] 